\title{
O AÇAÍ JÁ "PAROU" O CARIOCA? \\ ESTUDO QUALITATIVO DO CONSUMO DA POLPA DE AÇAÍ NA CIDADE DO RIO DE JANEIRO
}

\author{
Luís Alfredo C. Guimarães* \\ "Chegou no Pará, parou. \\ Tomou açaí, ficou"
}

\section{Introdução}

Esse artigo insere-se num projeto de pesquisa 1 que vem sendo realizado na região Amazônica, sobre a valorização de frutas tropicais pela agricultura familiar. Entre os frutos a valorizar, o açaí (Euterpea oleracea Mart.) se faz presente. Uma melhor apropriação por parte dos agricultores na venda de sua produção será concebida agregando-se valor a esse fruto, utilizando-se um processo de beneficiamento que poderá ser desenvolvido a partir de uma cooperativa de agricultores organizados.

Açaí pasteurizado é o processo de transformação proposto. Essa escolha visa obter um produto de qualidade, que possa conservar-se por mais tempo e sobretudo estar livre de contaminantes.

Esse tipo de processo é inovador. $\mathrm{O}$ açaí pasteurizado deverá em princípio ser comercializado em outros centros consumidores, pois, na região norte, principalmente no Estado do Pará, maior produtor e consumidor dessa fruta no Brasil, existe o hábito de se obter um açaí beneficiado (batido) para consumo imediato e, a curto prazo, um produto inovador seria de difícil aceitação.

\footnotetext{
* Economista, pesquisador associado do Núcleo de Altos Estudos Amazônicos / NAEA-UFPA.

${ }^{1}$ Projeto financiado pela Comunidade Econômica Européia, Convênio entre o Núcleo de Altos Estudos Amazônicos NAEA/UFPA e Unidade de Economia Rural/UCL, da Universidade Católica de Louvain/UCL, da Bélgica.
} 
Em algumas regiões do Brasil, o açaí vem ganhando novos adeptos, em especial na cidade do Rio de Janeiro, onde o consumo aumentou significativamente nos últimos 6 anos. O presente artigo deseja dar informações sobre o consumo, nesse município, de um produto similar, a polpa de açaí congelada, esperando dar subsídios para o lançamento de um novo produto, a polpa de açaí pasteurizada.

A metodologia adotada será rapidamente apresentada. A seguir, o fluxo de comercialização do açaí na cidade do Rio de Janeiro será ilustrado, apresentando-se os diversos atores envolvidos nessa atividade. Sendo o objetivo principal deste trabalho conhecer o consumidor final, as entrevistas foram feitas apenas em lojas de sucos e casas especializadas, tendo sido ouvidos comerciantes e consumidores. Serão apresentados os resultados dessas entrevistas e, em seguida, serão dadas algumas informações importantes para o bom aproveitamento do açaí.

\section{Metodologia}

Foram utilizados questionários dirigidos a vendedores (lojas de sucos e casas especializadas na venda de açaí) e consumidores da cidade do Rio de Janeiro. As entrevistas foram realizadas nos bairros da zona sul dessa cidade, local de maior consumo.

A pesquisa teve um aspecto qualitativo, buscando informações gerais que poderão contribuir para aumentar o conhecimento desse mercado. Buscou-se levantar pistas sobre as diversas tendências desse produto, segundo os entrevistados.

As entrevistas realizadas junto aos consumidores foram confrontadas com aquelas feitas nas lojas de sucos e casas especializadas, visto que esses estabelecimentos estão em contato direto com os consumidores. Além disso, importantes atacadistas foram também contatados, contribuindo para complementar as informações obtidas.

\section{Principais fluxos de comercialização do açaí na cidade do Rio de Janeiro}

O açaí é originário da região norte do Brasil. O principal fornecedor desse produto para a cidade do Rio de Janeiro é o Estado do Pará, maior produtor do Brasil. Em razão da sua alta perecibilidade, o fruto do açaí é beneficiado próximo às zonas produtoras, sendo sua polpa transportada em caminhões frigoríficos, em barras congeladas. Na figura 1, é apresentado 
o fluxo de comercialização do açaí polpa, proveniente do fabricante, até o consumidor final na cidade do Rio de Janeiro.

Como pode-se observar, o produto é adquirido principalmente pelos grandes atacadistas da CEASA e CADEC que são grandes entrepostos situados no Grande Rio. Eles vendem para supermercados, pequenos e médios revendedores que repassam esses produtos para lojas de sucos, casas especializadas, restaurantes assim como quiosques situados na praia. Existe ainda aqueles donos de casas de sucos e casas especializadas que vão diretamente aos atacadistas para obter o produto, sendo esta situação menos freqüente.

Os principais vendedores finais são as lojas de sucos e casas especializadas, que vendem entre outros produtos, a polpa de açaí transformada em suco. Pode-se encontrar também em alguns supermercados a polpa de açaí congelado. Os quiosques, são barracas situadas nas calçadas das diferentes praias da zona sul do Rio de Janeiro. De acordo com as informações obtidas, um número muito pequeno de quiosques, vendem açaí nestes locais. A possível explicação seria a falta de espaço, pois eles vendem diversos produtos tais como camarão, peixe frito, sanduíches, refrigerantes, cervejas, coco etc. Isso dificulta a venda do açaí pois ele é um produto que chega em barras congeladas e estas devem ser reprocessadas, necessitando de espaço para armazenar e mão de obra suplementar. Encontra-se polpa e suco de açaí, apenas em quiosques especializados em sucos.

\section{Lojas de sucos e casas especializadas}

\subsection{Características do produto}

O polpa de açaí chega no Rio de Janeiro em sacos plásticos de $1 \mathrm{~kg}$ ou em embalagens plásticas contendo saquinhos de $100 \mathrm{gr}$, sendo que a quantidade total pode variar de $400 \mathrm{~g}$ a $1000 \mathrm{~g}$. São transportados em grandes sacos plásticos e chegam ao destino congeladas. As diferentes formas de como ele é consumido serão apresentadas a seguir, assim como, as combinações com outras frutas, as quantidades de polpa e de outros ingredientes, as embalagens utilizadas, aspectos relativos a marca, preço e ao produto congelado.

a) Forma de consumo

O açaí é consumido no Rio de Janeiro, gelado, geralmente no copo, de 300 ou $400 \mathrm{ml}$, como suco, ou, numa tigela de $500 \mathrm{ml}$ para ser consumido com colher, quase sempre misturado com xarope de guaraná. O consumo 

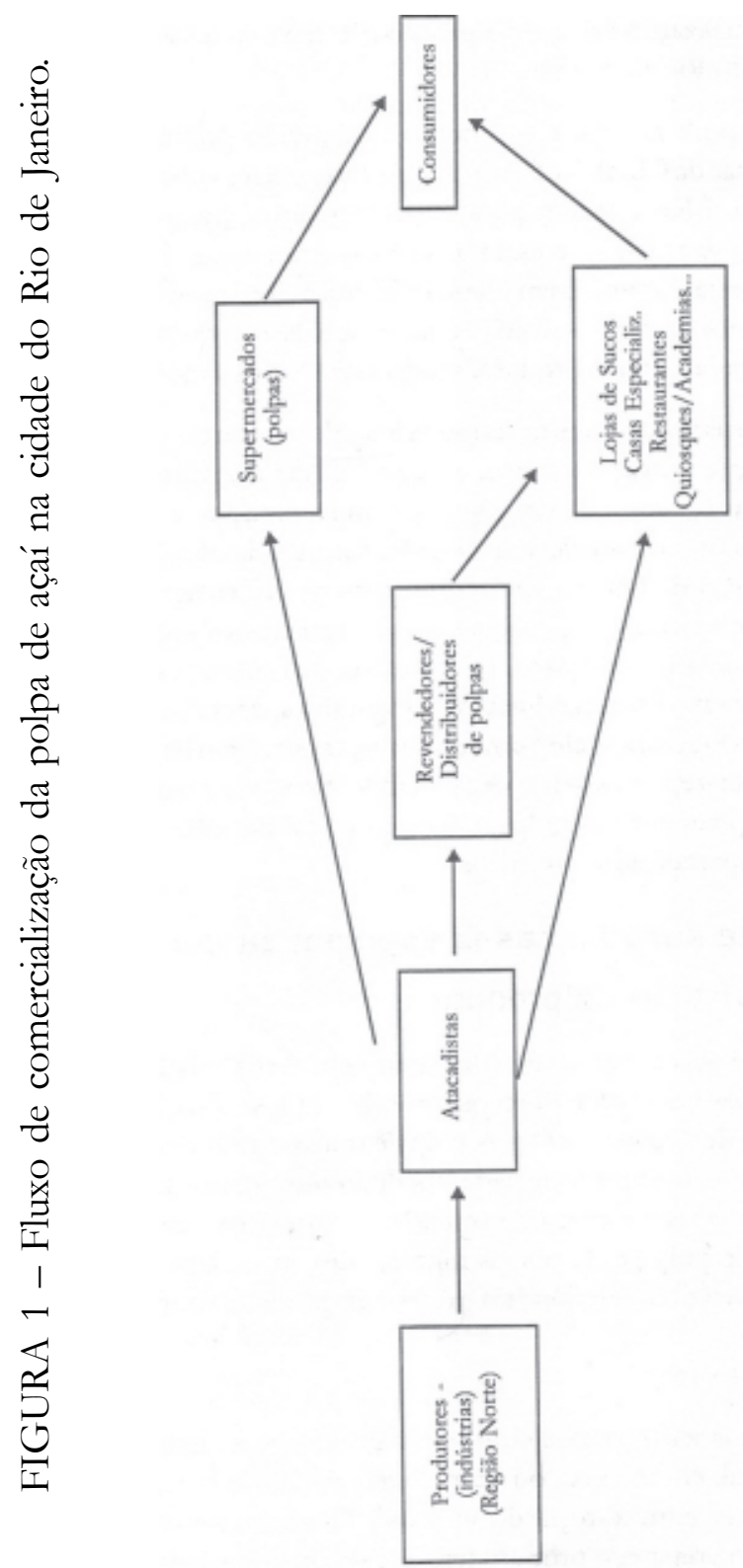
do açaí puro é insignificante. No preparo, o produto, tem que ser descongelado parcialmente. São adicionados xarope de guaraná e gelo picado, sendo o produto batido no liquidificador e servido em seguida.

Existem as misturas, em que frutas e diferentes ingredientes são acrescidos ao açaí com xarope de guaraná. Tanto no copo como na tigela, as frutas mais usadas individualmente são: banana, laranja, morango, acerola, mamão, manga, abacaxi, maracujá, abacate e kiwi.

Além dessas misturas, outras mais exóticas são também encontradas no mercado:

- açaí com xarope de guaraná, guaraná em pó, proteína de cálcio, acrescido ou não de granola ou tapioca;

- açaí com xarope de guaraná, guaraná em pó, ginseng (uma raiz), catuaba e marapuama;

- açaí com xarope de guaraná, leite de soja e mel de abelha.

Identificou-se ainda o coquetel de açaí, que consiste em açaí, licor de morango, vodca e piña colada.

\section{b) Proporção de polpa}

As proporções de polpa de açaí e de outros ingredientes utilizadas no preparo do suco variam de estabelecimento para estabelecimento. Podese encontrar:

- açaí no copo de $300 \mathrm{ml}$ : são usados entre 80 e 200 g de polpa, de 20 a $50 \mathrm{ml}$ de xarope de guaraná e o restante, gelo picado;

- açaí na tigela de $500 \mathrm{ml}$ : são usados entre 300 e $400 \mathrm{~g}$ de polpa, de 20 a 50 $\mathrm{ml}$ de xarope de guaraná e o restante, gelo picado; com granola ou tapioca, servem-se em pequenas porções;

- aquantidade de frutas acrescidas à mistura do açaí varia: acerola (5 a 6 unidades), laranja (2 unidades), banana (1 unidade) e morango (5 a 6 unidades).

Para o consumidor carioca, gelo picado misturado com o produto é essencial, pois o deixa gelado e, de certa forma, permite que ele apresente uma textura mais grossa e mais agradável.

Entre as formas acima mencionadas, a mais consumida é, sem dúvida nenhuma, o açaí com xarope de guaraná, pura e simplesmente, tanto no copo como na tigela. No último caso, o açaí é geralmente acompanhado 
de granola ou tapioca. No caso das misturas com frutas, o açaí com banana é o mais procurado.

\section{c) Embalagens}

Como citado anteriormente, no mercado do Rio de Janeiro, existem polpas de açaí embaladas em sacos plástico de $1 \mathrm{~kg}$ (barras) e também aquelas que variam de $400 \mathrm{~g}$ a $1 \mathrm{~kg}$, contendo saquinhos de 100 gramas.

As embalagens mais comercializadas são as barras de $1 \mathrm{~kg}$. São as preferidas pelos comerciantes por ser mais simples no momento do preparo. O outro tipo é mais aconselhado para quem vende pouco ou deseja consumir o produto em casa.

A opinião sobre a qualidade das embalagens varia bastante entre os lojistas. Alguns afirmam que as embalagens são boas e não vêem nenhum problema atualmente. Outros acham que elas são de péssima qualidade, não sendo resistentes arrebentando facilmente.

Para os atacadistas, as embalagens são de má qualidade. Muitas arrebentam durante o transporte ou apresentam sacos furados. Para o transporte, as polpas congeladas vêm embaladas em grandes sacos plásticos. Isto dificulta o seu armazenamento nas câmaras frigoríficas, elevando o seu custo em relação ao produto embalado em caixas de papelão.

\section{d) Marcas e preços}

Os preços da polpa adquirida pelos donos de loja de suco e casas especializadas são bastante variados. A grande maioria compra de algum distribuidor que adquire esse produto junto aos grandes atacadistas. Entre as marcas mais encontradas, foi possível identificar as seguintes: Maria Luiza, Dunorte, Copama, Polpará, Pinheiro, Maísa, Tropical, além de outras de menor expressão.

Para os lojistas, as barras de $1 \mathrm{~kg}$ apresentam preços que podem variar de $R$ \$ 1,60 a $R$ \$3,00. É mais comum encontrar preços situados na faixa de $R$ \$2,00 a $R$ \$2,50. Para a polpa de açaí vendida em embalagens de $100 \mathrm{~g}$ com $1 \mathrm{~kg}$ de polpa, o preço situa-se entre $\mathrm{R} \$ 2,90$ e $\mathrm{R} \$ 4,00$.

Alguns comerciantes afirmaram que existe uma tendência para classificar o açaí em tipo A, B e C, o que ocasionaria preços variados. Entretanto, essa afirmação merece um estudo mais profundo. Atualmente, os preços podem estar variando em função da quantidade adquirida por 
cada comerciante. Aquele que adquire maior quantidade tem a possibilidade de negociar a compra da matéria-prima em melhores condições.

Durante as entrevistas, pôde-se perceber que o preço da polpa de açaí diminuiu em relação ao ano passado. Isto se deveu à grande procura e à falta de matéria-prima naquele momento. Os preços, para os lojistas, situaram-se em patamares bem mais elevados, entre $\mathrm{R} \$ 3,00$ e $\mathrm{R} \$ 3,50$ o kg.

Finalmente, há o preço que os atacadistas pagam para obter a polpa de açaí. Ele se situa entre $\mathrm{R} \$ 1,30$ e $\mathrm{R} \$ 1,45$ na Ceasa, com frete incluído. Esses valores devem aumentar, pois existe uma grande procura no Rio de Janeiro e em outros Estados brasileiros, principalmente na cidade de São Paulo.

\section{e) Produto congelado}

Procurou-se identificar a opinião de lojistas, sobre a polpa de açaí congelada. As opiniões variam. Para alguns, essa forma não é inconveniente. Acreditam que não existe outra maneira de apresentar o produto. Outros, ao contrário, sentem dificuldade em preparar o açaí a partir da polpa congelada, pois "tem que degelar parcialmente, e não totalmente, pois estraga muito rápido. Depois são obrigados a picotar e bater no liquidificador", não esquecendo que ele deve ser bem gelado.

Foi sugerida aos comerciantes a possibilidade de se lançar um açaí pasteurizado, pronto para o consumo. Entre eles, alguns responderam que "seria complicado, pois o consumidor gosta de ver o produto sendo feito e este deve ser o mais próximo possível de um produto natural”. Em geral, se o produto mantiver as mesmas características da polpa congelada, eles se mostraram a favor. Exigindo, porém, que se faça um teste.

\subsection{Venda do produto}

a) Critérios de compra

Abaixo estão relacionados os critérios mais utilizados pelos comerciantes no momento da aquisição da polpa de açaí congelada:

- A cor deve ser bem escura, não devendo o produto apresentar aspecto muito cristalizado, o que indica a presença de água em excesso.

- A marca é também um fator importante. Eles procuram sempre que possível obter o produto do mesmo fabricante. 
- A confiança no vendedor: a grande maioria adquire o produto por telefone; dessa forma o vendedor deve ser pontual, não falhar e apresentar um produto de qualidade.

- A qualidade foi bastante citada. Desejam um produto que chegue a seus estabelecimentos congelados, e as barras devem estar em bom estado e inteiras.

- O sabor: os comerciantes procuram conhecer a opinião dos consumidores.

- Finalmente, o preço. Ele tem um papel fundamental entre os critérios observados. Alguns acham que o preço atual é elevado, apesar de ter sofrido uma queda em relação ao ano passado.

\section{b) Quantidade vendida de polpa de açaí}

A quantidade vendida pelos diferentes negociantes varia em função de seu estabelecimento, podendo ser maior se o estabelecimento é especializado no preparo de açaí.

A época de maior consumo de açaí é durante os meses de dezembro a abril. Existem lojas que chegam a vender nessa época do ano até $300 \mathrm{~kg}$ por dia. Nos outros meses do ano, o consumo de açaí tende a cair de forma expressiva. Isto porque a temperatura diminui, e o consumo de produtos gelados fica comprometido. Estima-se que a queda nas vendas fica em torno de 40 a 50\% em relação ao verão. Um comerciante afirmou que "agora no verão vendo 300 copos por dia, em outras épocas vendo entre 150 e 200 unidades".

Entre os vários sucos ofertados no mercado, o de laranja é o mais vendido durante todo o ano. Todavia, no período do verão, o açaí passa a ser um dos sucos mais procurados pelos consumidores, sofrendo concorrência ainda do suco de acerola puro ou misturado com laranja.

\subsection{Opiniões gerais do açaí por parte dos comerciantes}

No final de cada entrevista, sugeriu-se que os comerciantes emitissem opiniões complementares sobre o açaí. Eles afirmam que o açaí "é um produto que veio para ficar, pois o número de pessoas que o consomem aumentou muito nos últimos anos". Mas para algumas pessoas, existe modismo no consumo do açaí. Ele está na moda e nada garante que o consumo esteja consolidado.

Os comerciantes acreditam que o consumo do açaí passa por um ciclo ascendente e provavelmente poderá cair um pouco se algum outro 
produto novo aparecer. Como exemplo, foi citada a acerola. No início, houve uma explosão no consumo desse fruto, que era adquirido, sobretudo pela sua quantidade de vitamina C. Entretanto, o açaí chegou ao mercado e, aos poucos, foi tomando o lugar da acerola. Ela, por sua vez, não desapareceu do mercado, apenas seu consumo foi reduzido, mas está consolidado entre os amantes dessa pequena fruta. Os comerciantes afirmam que o açaí pode passar pelo mesmo ciclo.

Afirmaram também que ele não tende a desaparecer, posto que o açaí oferece um sabor único. "Açaí tem gosto de quê? De açaí. Não existe nada similar que possa substituí-lo".

Certos entrevistados asseguram que o açaí veio para ficar, mas tudo depende da mídia. Ela pode "desbancar" qualquer produto, uma vez que aponta problemas encontrados em determinados produtos, podendo o consumo diminuir ou mesmo cessar no mercado. Esta opinião está relacionada com a questão da qualidade. Um produto, para ser considerado bom, deve seguir todas as normas exigidas pelo órgãos fiscalizadores, caso contrário, pode perder um importante espaço no mercado.

\section{Consumidores}

\subsection{Perfil do consumidor de açaí no Rio de Janeiro}

Para tentar traçar o perfil dos consumidores, foram entrevistados consumidores e diversos comerciantes ligados ao mercado do açaí: atacadistas, donos de lojas de sucos e casas especializadas em produtos naturais e na venda de açaí, quiosques e os próprios consumidores. Foram colhidas informações sobre a faixa etária, a classe social e o sexo. Investigouse também se as pessoas que adquirem o açaí, o consomem por terem uma atividade a ele relacionada.

- Faixa etária: pessoas de todas as idades consomem açaí, contudo, o consumo é maior entre pessoas de 15 a 30 anos de idade, portanto entre os mais Jovens.

- Classe social: é importante ressaltar que a pesquisa descrita neste artigo foi realizada na zona sul da cidade do Rio de Janeiro, onde se concentra uma importante camada da população de renda mais elevada. É justamente nesse local que o consumo de açaí é mais elevado. Isso não significa dizer que o consumidor de renda mais baixa não o consome. Entretanto, pode-se perceber que o açaí é mais consumido pelas classes de renda média-média a média-alta. 
- Gênero: os homens consomem mais açaí que as mulheres. Isso estaria ligado ao fato de o açaí ser um produto extremamente gorduroso, o que leva as mulheres, em geral mais preocupadas em não adquirir peso, a consumir menos açaí que os homens.

- Atividades relacionadas: ao que parece, o açaí é consumido por pessoas que realizam diversos tipos de atividades. Todavia, muitas pessoas procuram o açaí por praticarem um esporte, e encontram neste produto um excelente repositor de energia. Outros acreditam que o açaí pode estar sendo consumido por pessoas que procuram um bom desempenho na vida, pois esse produto energético, saudável e natural, fazendo bem para a saúde.

\subsection{Hábito de consumo}

Neste item, serão apresentadas informações relativas ao consumidor, verificando-se desde quando as pessoas consomem açaí, com que freqüência, onde e quando o consomem, como começaram a consumi-lo e por que continuam a comprar esse produto.

\section{a) Quantidade consumida}

O consumidor de açaí da cidade do Rio de Janeiro, em geral, costuma beber ao menos um copo de $300 \mathrm{ml}$ de açaí por semana, principalmente no verão. Nessa mesma época, entre os entrevistados, podem-se encontrar pessoas que costumam comprar o produto mais de uma vez por semana e mesmo pessoas que o consomem todos os dias.

\section{b) Como começaram a consumi-lo}

Muitos dos entrevistados descobriram o açaí recentemente, há 1 ou 2 anos. Outros já o compram há pelo menos 4 a 5 anos. Existem ainda aqueles que já o conhecem e o adquirem há mais de 5 anos. Este último consumidor geralmente tem alguma ligação com a região originária do açaí, ou já morou ou tem parentes ou negócios na região norte do Brasil.

$\mathrm{Na}$ maioria das vezes, as pessoas começaram a consumir o açaí através de recomendação de amigos. Existem ainda aqueles que descobriram o produto assistindo às novelas e aos programas de televisão. As canções foram também uma forma de divulgação desse produto entre os consumidores. Partindo dessas informações, as pessoas mais interessadas procuraram conhecer melhor o açaí, lendo jornais e artigos de revistas mais especializadas. Até agora, a campanha mais importante foi o "boca a boca", isto é, nenhuma propaganda direta foi realizada. As pessoas 
experimentam o produto e, se gostam, divulgam suas opiniões em conversas informais.

Aqueles que continuam consumindo o açaí, o fazem simplesmente porque é energético, gelado, muito saboroso e alimenta bastante. Certos consumidores, por praticarem um esporte, procuram no açaí um produto que reponha energias. Existem ainda aqueles que bebem o açaí porque possui ferro: por recomendação médica, ingerem todos os dias ao menos um copo de $300 \mathrm{ml}$, e afirmam que vem surtindo efeito.

\section{c) Onde o consomem}

A maioria dos entrevistados não compra açaí para consumir em casa, pois, segundo eles, "dá muito trabalho e não tem muito tempo". Existe receio de errar na receita no momento de prepará-lo. Como o produto é congelado, o descongelamento, exige tempo. Além disso, alguns ingredientes devem ser adicionados à polpa. É necessário também utilizar um liquidificador resistente, pois o tipo mix, encontrado no mercado, não suporta o açaí semi-congelado com gelo picado. Finalmente, suja-se muito o local no momento da preparação. As informações obtidas sugerem que o consumidor não tem ainda o hábito de adquirir o açaí em polpa para prepará-lo em sua residência. Ao contrário, prefere consumi-lo nos diferentes estabelecimentos existentes. Quando não é consumido no próprio local, é levado para casa pronto, em embalagens para viagem.

De forma geral, os entrevistados acharam importante o local onde tomam o açaí. Existem locais que não sabem preparar corretamente o produto, seja na receita normal, açaí com xarope de guaraná, seja misturado com outros ingredientes. Para obterem maior rendimento na venda, certos comerciantes costumam adulterar o produto final, adicionando outros ingredientes, obrigando o consumidor a mudar de loja. Quando o produto é bom, geralmente é consumido no local. Os consumidores procuram sempre lojas que estejam situadas perto de casa e do trabalho. Eles dão preferência às lojas de suco e às especializadas em açaí e produtos naturais.

\section{d) Quando o consomem}

Nas várias formas de preparo, o açaí pode ser consumido como café da manhã, como complemento de refeição, ou seja, entre 10 e 11 horas e entre 15 e 16 horas, e mesmo após o jantar. Ele pode ser ainda considerado, pura e simplesmente, uma refeição. Em suas várias formas de consumo, ele pode ser acompanhado de salgados (pastéis, sanduíches 
naturais, pizzas, além de outros), sobretudo entre as refeições. Quando consumido no almoço ou no jantar, como refeição é acompanhado apenas de granola ou tapioca.

\subsection{Critério de compra do consumidores}

Entre critérios levados em consideração no momento da compra, os mais citados foram: a textura, a cor, o preço e a marca do produto.

A maioria prefere um açaí de textura grossa, bem consistente. Em menor número há aqueles que preferem um produto com uma textura média. Nas duas formas, ele deve estar bem gelado. (É importante salientar que não foi identificada, durante a pesquisa, a concentração da polpa de açaí que chega ao Rio de Janeiro. Mas, de acordo com as informações obtidas junto aos diversos comerciantes, as polpas não são muito concentradas, isto é, a relação polpa/água é baixa, uma quantidade importante de água é adicionada ao produto. Portanto, quando o consumidor deseja um suco "grosso", a ele é adicionado gelo picado na polpa semi-congelada, que, batida junto com todos os ingredientes, contribui para a obtenção de um produto gelado e de textura bem grossa).

Para alguns a cor "assusta no início", mas depois se acostumam. Ela deve ser de preferência escura, cor de vinho tinto.

O preço também é levado em consideração no momento da compra do açaí. Os consumidores garantem que alguns comerciantes costumam cobrar preços muito alto pelo produto consumido no copo e na tigela.

A marca também foi apontada como critério de avaliação no momento da compra por parte dos consumidores. Entretanto, esse critério foi o menos considerado, pois nem todos têm acesso à matéria-prima quando consomem o açaí nas lojas. Esse critério é mais importante para os donos de loja de sucos, atacadistas e outros comerciantes (ver item d do ponto 3.1).

Quanto aos pontos negativos ligados ao produto, os consumidores disseram que o fato de ser gorduroso prejudica um pouco e muitos deixam de consumi-lo mais vezes porque engorda (foi sugerido por alguns consumidores que se invente um açaí tipo "light").

Como dito anteriormente, a textura do produto tem um papel importante no momento da compra. Muitos não gostam quando o açaí não é bem batido e ficam depositadas pequenas pedras de gelo, tornandose inconveniente o seu consumo. 
Para alguns, o sabor às vezes não é bom. Existem estabelecimentos que vendem açaí com gosto amargo, outros com gosto de terra e ainda certas lojas vendem açaí misturado com outros produtos para dar mais consistência, mesmo que o consumidor não tenha pedido. Isso altera significativamente o sabor e a textura.

Ser um produto gelado é uma exigência dos consumidores, mas para alguns gelado em demasia dificulta seu consumo, ficando difícil tomá-lo como suco. Bebe-se lentamente para evitar dores de cabeça.

\subsection{Preços, produtos substitutos e um novo produto sob a ótica do consumidor.}

Nesta seção, serão apresentadas as diferentes opiniões dos entrevistados sobre o preço, identificando-se até quanto eles pagariam pelo açaí na sua forma de consumo atual. Procura-se saber ainda qual é, para eles, o produto substituto do açaí, assim como se estariam interessados num novo produto, um açaí pasteurizado, pronto para o consumo.

\section{a) Preço}

Como apresentado anteriormente, o açaí é consumido em diversas formas, tanto no copo de $300 \mathrm{ml}$ como em tigelas de $500 \mathrm{ml}$. Para o açaí consumido no copo, os entrevistados estariam dispostos a pagar valores situados entre $\mathrm{R} \$ 1,50$ e $\mathrm{R} \$ 2,00$. Todavia, outros consumidores aceitariam pagar um pouco mais, valores situados entre $\mathrm{R} \$ 2,50$ e $\mathrm{R} \$ 3,00$. Para o açaí consumido na tigela, os entrevistados concordam em pagar um pouco mais. O preço situa-se na faixa de $\mathrm{R} \$ 3,00$ a 3,50, sendo que alguns aceitariam pagar até $\mathrm{R} \$ 4,00$ pelo açaí em suas diversas formas.

b) Produto substituto

Quanto a um produto substituto, os fiéis consumidores de açaí acham difícil existir um outro similar. Se desejam açaí e não encontram, vão procurar em outro estabelecimento até encontrarem. Caso contrário, não pedem nada. Só aceitam substituir por outra forma de consumo do açaí e não por um outro substituto.

Para aqueles consumidores não tão fanáticos, os produtos substitutos são diversos, dada a grande variedade de sucos encontrada no mercado. Caso cheguem a uma determinada loja e não encontrem açaí, pedem então suco de morango, goiaba, mamão com laranja, fruta de conde, cupuaçu, 
limonada, laranja, kiwi com morango, tangerina, maracujá, manga, graviola, acerola, acerola com laranja, ou ainda um refrigerante, e mesmo xarope de guaraná acrescido de água ou leite de soja ou ainda com mate.

c) Novo produto

Pretendemos, também, conhecer o consumo de açaí na cidade do Rio de Janeiro visando fornecer informações que poderão ajudar no lançamento de um produto novo que está em fase de conclusão. O produto é o açaí pasteurizado, conservado a temperatura ambiente, pronto para o consumo. A pasteurização permitiria a obtenção de um produto livre de contaminantes. Entretanto, para se conservar em temperatura ambiente, será necessário o acréscimo de algum produto ácido, visto que o açaí apresenta um ph (medida utilizada para se conhecer a acidez de um produto) elevado, o que leva a uma deterioração mais rápida. Para baixar o ph, será necessário acrescentar um produto natural, como frutas ácidas, ou artificial. Este último não seria recomendado, pois o açaí perderia as características básicas e fugiria das exigências dos consumidores.

Partindo dessa lógica, perguntou-se aos consumidores se eles estariam interessados numa fórmula de açaí pronto para ser consumido, já misturado com um produto ácido, mas natural, como uma fruta por exemplo e os ingredientes normais. Além disso, procurou-se saber com qual ou quais frutas, eles aceitariam misturar com o açaí.

Em sua maioria, os entrevistados mostraram-se interessados e prontos para experimentar essa nova forma de consumo. Todavia, alguns não aceitariam essa mistura ou por preferirem o açaí em sua forma atual, sem nenhuma mistura, ou por apresentarem problemas de saúde, não podendo ingerir nenhum produto ácido.

Aqueles que aceitariam experimentar uma nova mistura do açaí, sugeriram as seguintes frutas ácidas: acerola, morango, laranja, maracujá, abacaxi, limão, kiwi, tangerina, não esquecendo que essa mistura deve conter sempre xarope de guaraná.

\section{Informações complementares}

Estimou-se junto aos principais comerciantes (atacadistas em sua maioria) o volume comercializado de polpa de açaí, proveniente da região norte. Em média, 200 toneladas mensais chegam à Ceasa e à Cadec, locais onde estão concentrados os principais atacadistas. O produto é 
transportado em caminhões frigoríficos com capacidade de até 24 toneladas de polpa congelada. Segundo alguns negociantes, o valor do frete para o trajeto Belém-Rio é de $\mathrm{R} \$ 2.000,00$.

Os atacadistas em geral são proprietários de câmaras frigoríficas de grande porte. Se necessitam de mais espaço, alugam outras câmaras frigoríficas. São bem capitalizados, o que lhes permite trabalhar com grandes estoques e adquirir seus produtos em melhores condições. A título de exemplo, tem-se o caso do açaí de Belém. A fruta, proveniente da região das ilhas de Belém, além de municípios próximos (açaí de melhor qualidade produzido na época de preço mais baixo, entre os meses de setembro a dezembro), é beneficiada, e os atacadistas adquirem grandes quantidades de polpa durante essa época, estocando e negociando esse produto até abril. A partir desse período, é o açaí da Ilha de Marajó que chega a Belém, mas não é tão bem aceito. Nessa época, os atacadistas compram açaí de outros Estados da região Norte.

Quanto à qualidade do produto, esses negociantes afirmaram que existe uma tendência para se classificar o açaí em tipo "A", "B" ou "C", em função da quantidade de matéria seca encontrada no produto. Eles alertam que o consumidor enfrenta problemas com a qualidade, pois algumas lanchonetes acrescentam água, banana e abacate em grande quantidade, para dar mais consistência ao açaí, adulterando o produto final. Faz-se urgente, portanto, a implementação das normas do Ministério da Agricultura, que foram estabelecidas recentemente.

Os principais atacadistas estimam que, da polpa de açaí proveniente da região norte que chega à cidade do Rio de Janeiro, 70\% seguem para a zona sul, principalmente para os lojas de sucos e casas especializadas. $20 \%$ vão para outros pontos da cidade, como zona norte e centro, e os $10 \%$ restantes destinam-se a outras cidades do Brasil e ao interior do Estado do Rio de Janeiro.

Para termos uma idéia da importância que o açaí vem alcançando em mercados fora da região norte, serão propostas algumas hipóteses e depois essas informações serão confrontadas com os dados de produção do açaí nos principais Estados da região norte.

\section{Informações básicas}

- 1 lata de $14 \mathrm{~kg}$ de fruto representa $10 \mathrm{~kg}$ de polpa congelada.

- Preço médio do kg de polpa pago no Rio de Janeiro (sem frete): - R\$1,29.

- Quantidade ofertada no Rio de Janeiro atualmente: 2.400 toneladas/ano. 


\section{Hipóteses}

- Se a quantidade ofertada no RJ aumentar em 50\%: 3.600 t/ ano.

- Se a quantidade ofertada na cidade de SP for o dobro do RJ: 7.200 t/ano.

- Se a quantidade ofertada em 7 importantes capitais brasileiras (Belo Horizonte, Brasillia, Goiânia, Vitória, Salvador, Recife e Fortaleza) for à atualmente ofertada na cidade do RJ: 2.400 t x $7=16.800$ t ano.

- O total final seria: $27.600 \mathrm{t} /$ ano de polpa congelada.

Com a quantidade de frutos de $38.640 \mathrm{t} /$ ano, a quantidade de latas de $14 \mathrm{~kg}: 2.760 .000$ latas/ano e a receita/preço médio em $\mathrm{R} \$ 35.604 .000,00$ por ano $(\mathrm{R} \$ 1,29$ o kg da polpa); significa dizer que $\mathrm{R} \$ 35.604 .000,00$ será o valor que a região norte deve receber pela venda de polpa congelada, sendo aproximadamente 90\%, destinados ao Estado do Pará.

Se confrontarmos esses valores descritos acima com os dados de produção de açaí de 1992 fornecidos pelo IBGE - 124.556 toneladas -, chega-se à seguinte conclusão:

A quantidade de fruto transformada em polpa, utilizada na hipótese acima, que foi de 38.640 t, representa $31 \%$ da produção estadual de 1992. O Estado do Pará é o maior produtor, e nesse ano contribuiu com 94,33\% do total da produção, ou seja, 117.488 t. Comparando-se com as $38.640 \mathrm{t}$ da hipótese anterior, isso significa $32 \%$ da produção desse Estado.

É importante frisar que os valores hipotéticos sugeridos acima não devem fugir muito da realidade. Além disso, a quantidade de fruto a ser transformada em polpa nas hipóteses sugeridas acima representa uma quantidade superior à produção de alguns municípios considerados importantes produtores do Estado do Pará.

\section{Conclusão e recomendações}

A pesquisa aqui realizada teve por objetivo conhecer o mercado consumidor de açaí, polpa, na cidade do Rio de Janeiro. Percebe-se claramente que a demanda vem aumentando de forma significativa. Isso deve ampliar as perspectivas de investimento nesse setor.

A polpa de açaí é vendida congelada, sendo sua qualidade bastante variada. As concentrações variam de produto para produto. Recentemente, foram estabelecidos normas e padrão de qualidade para a polpa de açaí. Isso deverá organizar um pouco o mercado, permitindo uma concorrência mais justa. 
Um açaí pronto para o consumo poderá ser bem aceito pelos supermercados e quiosques situados nas praias. Nos primeiros, a polpa seriam destinadas àqueles que irão consumi-la em casa. Nos segundos, os quiosques, a falta de espaço e a dificuldade de armazenamento seriam resolvidos com um açaí já pronto para ser consumido, faltando apenas acrescentar os ingredientes. Quanto às lojas de sucos e casas especializadas, pistas apontam para uma possível aceitação por parte dos comerciantes. Isto porque facilitaria o preparo do suco. Todavia, um teste junto a esses lojistas deve ser realizado, pois as opiniões são controvertidas, e, desse modo, evitar-se um possível fracasso no lançamento do novo produto.

O açaí está na moda ou já foi aceito completamente pelo consumidor da cidade do Rio de Janeiro? Para a maioria dos entrevistados, o consumo do açaí não é mais um modismo, isto porque já faz mais de 5 anos que ele apareceu e vem ganhando cada vez mais adeptos.

A procura deve ainda aumentar não apenas no município analisado, mas também em outras importantes cidades brasileiras, como é o caso da cidade de São Paulo. No Estado de São Paulo, ele apareceu primeiramente nas praias paulistas. Atualmente, existem diversas lojas vendendo esse produto na capital. Ele é consumido da mesma forma que no Rio de Janeiro. Isto pode ser comprovado em um artigo que foi publicado na Folha de $S$. Paulo, no mês de janeiro de 1998: "Açaí é a nova moda do verão do El Nino". O artigo reproduz a opinião do proprietário que começou seu negócio com o açaí no mês de maio de 1997 e hoje vende até 2 toneladas por mês no verão, tendo seu faturamento dobrado após iniciar a venda da polpa de açaí na forma de suco e na tigela.

Um outro artigo da revista Isto É, Dinheiro, de 15 de abril de 1988, na seção mercado, apresenta "A frutinha que vale ouro". Três sócios de uma distribuidora paulista, só no mês de janeiro, venderam o mesmo que em todo o ano de 1997, R $\$ 87$ mil. Esse mesmo estabelecimento vendia até 600 quilos de polpa por mês, e já no primeiro mês de janeiro haviam negociado 24 toneladas de polpa. Como o consumo diminui de forma acentuada no inverno, os sócios desse empreendimento já se preparam para lançar uma bebida energética, a Power Açaí, para ser consumida também nessa época.

Estima-se que, aumentando a procura pela polpa de açaí em outros Estados, a tendência de queda nos preços que vem se verificando no Rio de Janeiro, deve sofrer alteração. Eles certamente deverão aumentar.

As informações obtidas acima são bastante promissoras. Percebe-se claramente que o interesse pelo açaí nos locais onde antes ele era inexistente 
vem aumentando de maneira considerável. Algumas recomendações serão sugeridas a seguir, visando um melhor aproveitamento do açaí pelos Estados produtores, cujos governos deverão ter um papel fundamental:

- incentivar o crédito no sentido de estimular o aumento da produção, assim como a implantação de unidades de beneficiamento desse fruto próximo às zonas de produção;

- fiscalizar, acompanhar e incentivar a produção de produtos de boa qualidade;

- fornecer condições mínimas para a realização de um melhor escoamento da produção, assim como criar centrais de armazenamento adequadas;

- incentivar o consumo do açaí a partir de propagandas que sejam veiculadas nas diversas regiões do Brasil;

- incentivar pesquisas de mercado, tanto no nível nacional como no nível internacional.

$\mathrm{Na}$ realidade, é importante fornecer meios para que sejam criadas bases sólidas para que o açaí possa se consolidar enquanto produto tipicamente da região norte. Criando-se boas estruturas de informação, infra-estrutura básica, mercado organizado etc., o açaí não deverá sofrer concorrência de um produto igual ou transportado daqui para outras regiões do país, como aconteceu com a borracha, um produto originário da Amazônia.

\section{Bibliografia}

FOLHA DE S. PAULO, Açai é a nova moda do verão do El Nino, 10 de fevereiro de 1998.

ISTO É, DINHEIRO, A Frutinha que vale ouro, n 33, 15 de abril de 1998.

LAMBIN, J.-J. Le marketing stratégique: une perspective européenne. Paris, Ediscience internacional, 1994, p.116-123

NASCIMENTO, M. J. M. Mercado e comercialização de frutos de açaí. Belém, Relatório de Pesquisa, Tomo III, Universidade Federal do Pará, CFCH, WWF, 1992. 106p.

SANTOS, T. M. GUimarÃES, L. A., RODRIGUES, D. M., HENRY DE FRAHAN, B., Comercialização do açaí no Estado do Pará, Brasil. Belém: IDESP. Relatório de Pesquisa, Coordenadoria Sócio-Econômica/Université Catholique de Louvain. Faculté de Science Agronomique. Unité d'Economie et de Sociologie Rurales, 1996, 26p.

RODRIGUES, D. M. GUIMARÃES, L. A., Análise dos preços de algumas frutas frescas e transformadas no Estado do Pará. Belém: Núcleo de Altos Estudos Amazônicos-UFPA/Unité d'Economie et de Sociologie Rurales, 1996. 17p. 